\title{
Early relations between language development and the quality of mother-child interaction in very-low-birth-weight children
}

\section{Stolt, Suvi}

2014-05

Stolt , S , Korja , R , Matomaki , J , Lapinleimu , H , Haataja , L \& Lehtonen , L 2014 , ' Early relations between language development and the quality of mother-child interaction in very-low-birth-weight children ' , Early Human Development , vol. 90 , no. 5 , pp. 219-225 . https://doi.org/10.1016/j.e

http://hdl.handle.net/10138/299224

https://doi.org/10.1016/j.earlhumdev.2014.02.007

publishedVersion

Downloaded from Helda, University of Helsinki institutional repository.

This is an electronic reprint of the original article.

This reprint may differ from the original in pagination and typographic detail.

Please cite the original version. 


\title{
Early relations between language development and the quality of mother-child interaction in very-low-birth-weight children
}

\author{
S. Stolt ${ }^{\text {a, }}$, R. Korja ${ }^{\text {b }}$ J. Matomäki ${ }^{c}$, H. Lapinleimu ${ }^{\text {c }}$, L. Haataja ${ }^{\text {d }}$, L. Lehtonen ${ }^{c}$ \\ a Dept. of Behavioural Sciences and Philosophy, University of Turku, Turku, Finland \\ ${ }^{\mathrm{b}}$ Dept. of Child Psychiatry, Turku University Hospital and University of Turku, Finland \\ c Dept. of Pediatrics, Turku University Hospital and University of Turku, Turku, Finland \\ ${ }^{\mathrm{d}}$ Dept. of Pediatric Neurology, Turku University Hospital and University of Turku, Turku, Finland
}

\section{A R T I C L E I N F O}

\section{Article history:}

Received 15 October 2013

Received in revised form 17 February 2014

Accepted 19 February 2014

\section{Keywords:}

Very-low-birth-weight children

Preterm children

Language development

Mother-child interaction

\begin{abstract}
A B S T R A C T
Background: It is not clearly understood how the quality of early mother-child interaction influences language development in very-low-birth-weight children (VLBW).

Aims: We aim to analyze associations between early language and the quality of mother-child interaction, and, the predictive value of the features of early mother-child interaction on language development at 24 months of corrected age in VLBW children.

Study design: A longitudinal prospective follow-up study design was used.

Methods: The participants were 28 VLBW children and 34 full-term controls. Language development was measured using different methods at 6,12 and at 24 months of age. The quality of mother-child interaction was assessed using PC-ERA method at 6 and at 12 months of age.

Results: Associations between the features of early interaction and language development were different in the groups of VLBW and full-term children. There were no significant correlations between the features of mother-child interaction and language skills when measured at the same age in the VLBW group. Significant longitudinal correlations were detected in the VLBW group especially if the quality of early interactions was measured at six months and language skills at 2 years of age. However, when the predictive value of the features of early interactions for later poor language performance was analyzed separately, the features of early interaction predicted language skills in the VLBW group only weakly.

Conclusions: The biological factors may influence on the language development more in the VLBW children than in the full-term children. The results also underline the role of maternal and dyadic factors in early interactions.
\end{abstract}

(c) 2014 Elsevier Ireland Ltd. All rights reserved.

\section{Introduction}

The interest on early language development of the children born at low gestational age ( $<32$ gestational weeks) and/or with very-lowbirth-weight ( $\leq 1500 \mathrm{~g}$; VLBW) has grown during the last decade [1-4]. These children as a group have been shown to have weaker language skills at the end of the second year than full-term children $[1,4]$. The difference in language skills between the groups of preterm and full-term children has also been shown to increase as children grow [5-7]. It is not clearly understood what factors are influencing on the language development in preterm children. For example, it is not known in detail what kind of influence the quality of early

\footnotetext{
* Corresponding author at: Department of Behavioural Sciences and Philosophy. Assistentinkatu 7, 20014, University of Turku, Finland. Tel.: + 35823338786.

E-mail address: Suvi.Stolt@utu.fi (S. Stolt).
}

mother-child interaction has on the early language development in VLBW children.

It is controversial if there are differences between early motherchild interactions in preterm and full-term children [8-10]. There are many reasons why early interactions of preterm children and their mothers may differ from those of the full-term children. Women build up mental representations of being a mother during the pregnancy. The preterm birth interrupts this process. An interrupted representation process as well as traumatic birth experience and early separation may influence early mother-child interaction of the preterm child and her mother [11]. Mothers of the preterm children have been reported to suffer from distress and stress more often than mothers of full-term children $[8,9]$, and this has also been shown to influence the motherchild interaction [8]. On the other hand, preterm children have been shown to have more problems with self-regulation and more stress than full-term children at least in the middle of the first year [12]. In addition, the prevalence of neurodevelopmental impairments has been shown to be higher among preterm children if compared to full- 
term children $[13,14]$. Preterm children may also suffer from physical diseases such as respiratory distress syndrome and bronchopulmonary dysplasia, or they may have intraventricular hemorrhage at an early age. All of these matters may contribute to the infant attachment, maternal attachment representation and to the early interactions between a preterm child and a caregiver [15]. The child's capacity to participate in communication may influence maternal interactive behavior: the problems in communication and development may make it difficult for the mother to build reciprocal interchanges with the baby.

Language develops in the interaction. It is unclear which of the following factors, maternal, infant or dyadic, are critical when aiming to support preterm children's language development. Some findings have been presented [16-18]. Mother's sensitivity and consistent responsiveness $[16,17]$ and the mother's use of attention-focusing gestures with relevant descriptive speech in mother-child interactions [18] have been shown to support later cognitive-language/language performance of preterm children. On the other hand, very early intervention did not have an effect on preterm children's communication skills at 12 months of age [19]. The intervention in this study aimed to support parent's positive representations of her child and to help the parent to be responsive and sensitive to her child's needs [19]. Furthermore, it is not clearly understood if there are critical time windows for the language development of preterm children during the first years of life $[20,21]$. This information would be helpful when planning the timing of early intervention for preterm children.

In our earlier study of nearly the same, slightly larger group of children as described here, the quality of mother-child interaction was nearly comparable between the groups of VLBW and full-term children at 6 and 12 months of age [10]. The only differences that were found between the groups were in two infant factors (infant's sober and withdrawn mood, infant's quality of play, interest and attention) at twelve months of age. However, despite the fact that the quality of motherchild interactions was mostly parallel, VLBW children had acquired significantly less words to their receptive lexicon [4] and less gestures [22] between 9, 12 and 15 months of age. In addition, VLBW children used less inflectional morphology in their spontaneous speech in motherchild interactions [23] and had weaker language performance when measured using a formal test at two years of age than full-term controls [4]. Based on these earlier findings, in the present prospective longitudinal study we aimed to analyze of how the quality of early mother-child interaction and early language development are associating with each other in the VLBW children. We also wanted to analyze the predictive value of the quality of early mother-child interaction on language development of VLBW children. The aim was also to get information of what features of early mother-child interaction (maternal/infant/dyadic factors) are critical for the early language development in VLBW children.

\section{Methods}

\subsection{Participants}

The subjects were 28 VLBW children (birth weight $\leq 1500 \mathrm{~g}$ ) and their 34 full-term controls ( $>37$ gestational age). The VLBW children were born in Turku University Hospital between 7/2001 and 5/2005. The controls were born between $11 / 2001$ and 4/2002. All 62 children were their mother's first-born children and were growing in Finnish speaking monolingual families.

The group of VLBW children is heterogeneous as was the present sample as well. Four VLBW children in the present sample had a diagnosis of bronchopulmonary dysplasia (BPD) (see Table 1 for the background characteristics). Three VLBW children had a neurological diagnosis (cerebral palsy, hearing impairment, cognitive development impairment) at two years corrected age. All full-term children were developing normally. There were more children with weak cognitive development measured using Mental Developmental Index value (MDI) of Bayley Scales of Infant Development-II [24] at two years of

\section{Table 1}

Background characteristics of the very-low-birth-weight (VLBW) and full-term (FT) children. The values presented are numbers and percentages of the children. If mean, standard deviation or median values are used, it is marked separately.

\begin{tabular}{|c|c|c|}
\hline & $\begin{array}{l}\text { VLBW children } \\
N=28\end{array}$ & $\begin{array}{l}\text { FT children } \\
\mathrm{N}=34\end{array}$ \\
\hline & $\mathrm{n}(\%)$ & $\mathrm{n}(\%)$ \\
\hline Birth weight (g); mean (SD) & $1048(264)$ & $3550(408)$ \\
\hline Gestational age in weeks; mean (SD) & $28(2)$ & $40(1)$ \\
\hline Females/males & $10(18) / 36(64)$ & $16(18) / 47(53)$ \\
\hline Apgar 5 min.; median & 8 & 9 \\
\hline Bronchopulmonary dysplasia & $4(14)$ & \\
\hline Cerebral palsy & $1(4)$ & - \\
\hline Hearing impairment & $1(4)$ & - \\
\hline $\mathrm{MDI}<70(-2 \mathrm{SD})$ at $2 ; 0$ & $1(4)$ & - \\
\hline RDLS III $<70(-2$ SD $)$ at $2 ; 0$ & $1(4)$ & - \\
\hline RDLS III between 70 and 85 ( -2 SD) at 2;0 & $9(32)$ & $1(3)$ \\
\hline \multicolumn{3}{|l|}{ Mother's basic education } \\
\hline$<9$ years & - & - \\
\hline $9-12$ years & $9(33)$ & $9(27)$ \\
\hline$>12$ years & $18(67)$ & $25(73)$ \\
\hline
\end{tabular}

MDI - mental developmental index in Bayley Scales of Infant Development II; RDLS III Reynell Developmental Language Scores III.

Note: the information on mother's basic education was available from 27 VLBW children only.

age in the VLBW group than in the control group. In addition, there were more VLBW children in the present sample with weak language skills when measured using the Reynell Developmental Language Scales III (RDLS) ([29,30], see also 4]) at two years of age if compared to the full-term children's group (Table 1). The present groups did not differ in terms of mothers' basic education, $\chi^{2}(1)=0.34, p=0.56$.

\subsection{Measures}

\subsubsection{Early language development}

The development of early vocalizations during the first year was followed using the Checklist for the Development of Early Vocalizations (CDEV) [25]. Detailed information on data collection is presented in our earlier study [26]. The CDEV is a structured maternal report method and it has been validated in a sample of Finnish children $(N=88)$ [25]. The information of the use of reduplicative babbling strings (e.g./nananana/ or/bababababa/) at 6 months of age (yes/no; corrected age for VLBW children) was used in the present study.

The information on early lexical development at 12 and at 24 months of age (corrected ages for VLBW children) was gathered using the Finnish version of the MacArthur Communicative Development Inventory (CDI; FinCDI) $[27,28]$. The FinCDI is a structured maternal rating method and it has been validated in a sample of Finnish children $(\mathrm{N}=95)$ [27]. The detailed information on how the data was gathered is presented in our earlier study [4]. The following data was used in the present study: receptive and expressive lexicon size at 12 months of age, and expressive lexicon size at 24 months of age.

The information on early grammatical development at 24 months of age (corrected age for VLBW children) was gathered using the FinCDI and by analyzing child's spontaneous speech in videotaped motherchild interactions (see [23] for the detailed information on the data collection). The following grammatical data was used in the present study: the utterance length (i.e. the mean length of the three longest utterances calculated in morphemes, M3L value) and the number of different morphological endings that a child was using during the ten minute sample of mother-child interaction.

Language skills were assessed using the RDLS III ([29,30], see also [4]) at two years of corrected age. The RDLS is a well-known language test including a scale for receptive and expressive language skills, and it has been validated for Finnish children [30]. Both scales were used in the present study. 


\subsubsection{Quality of mother-child interaction}

The Parent-child Early Relational Assessment (the PC-ERA) method [31] was used to get information on the quality of early interactions at 6 and at 12 months of age (corrected ages for VLBW children). Detailed information on the data was collection has been presented [10]. Mother-child interactions were videotaped at both age points, and the PC-ERA assessment was made from the 5 minute sample of videotaped interaction. The PC-ERA assessment consists of 62 items ( 29 parental, 25 infant and 8 dyadic items). For the analysis, nine factors were modified from these items $[32,10]$. Three factors reflect maternal, three infant and three dyadic features (the factors are presented in Table 2). High PC-ERA scores indicate positive behavior.

\subsubsection{Analysis}

The Wilcoxon two-sample test was used to analyze if the child's ability to use reduplicative babbling strings had a significant effect on the PC-ERA factors at six months of age. The Spearman's correlation coefficient values were calculated to get information on the possible associations between the PC-ERA factors and early language. The predictive value of the features of early mother-child interaction at 6 and at 12 months of age to the poor language performance (RDLS III total score $<85$ ) at two years of age was analyzed using the area under the roc-curve (AUC) values. AUC-values are interpreted as follows: excellent predictive value $1.00-0.90$, good $0.80-0.90$, moderate $0.70-0.80$, poor $0.60-0.70$, and fail $<0.60$ [33]. There was only one child with weak language skills (RDLS III $<85$ ) in the control group. Thus, AUC-values were calculated only for the VLBW children.

\section{Results}

3.1. Relations between the quality of mother-child interaction at 0;6 and at 1;0 and language development at the same age

The child's ability to use reduplicative babbling strings did not influence on the PC-ERA factors when children were 6 months of age in the VLBW group (Table 2). The results were the same if three children with major neurological impairment were left out of analysis. In full-term children, there was a significant difference in two of the infant PC-ERA factors (Table 2) if the child had begun to use reduplicative babbling strings.

None of the PC-ERA factors that were analyzed from mother-child interactions at 12 months of age correlated significantly with the language variables measured at the same age in the VLBW group (Table 3). The results were the same even if the three VLBW children with neurological diagnosis were excluded. In the control group, two dyadic PC-ERA factors correlated significantly with receptive lexicon size and one infant PC-ERA factor with expressive lexicon size at this age.
3.2. Correlations between the quality of early mother-child interaction and later language development

In the VLBW group, five (i.e. two dyadic, two infant and one maternal factor) out of nine PC-ERA factors that were measured at 6 months of age correlated significantly with at least one of the language measure at 2 years of age (Table 4). If three VLBW children with major neurological impairment were excluded, the same significant correlations were detected. In addition, the maternal positive affective involvement $\left(r_{s}=0.46, p=0.03\right)$ factor correlated significantly with the number of morphological inflections that a child was using in mother-child interactions at 2 years of age, and the correlation between infants positive affect and the number of morphological inflections a child used in videotaped interactions at two years of age was nearly significant $\left(r_{s}=0.41, p=0.05\right)$. In full-term children, six (i.e. three dyadic, one infant and two maternal factors) out of nine PC-ERA factors measured at 6 months of age correlated significantly with later language skills.

Only one (i.e. maternal positive communication) of the PC-ERA factors that were measured at 1;0 correlated significantly with language skills a year later in the VLBW group (Table 5). The result was the same even if the three VLBW children with major neurological diagnosis were excluded. On the contrary, seven (three dyadic, two infant and two maternal factors) PC-ERA factors correlated significantly with later language skills in the full-term children (Table 5). The dyadic factors especially correlated significantly with later language measures.

\subsection{Predictive values of PC-ERA factors}

None of the measured PC-ERA factors predicted well or excellently later language performance in either of the measured age points (Table 6). However, two maternal factors had fair predictive value, one at six months of age and the other one at one year of age. Thus, when maternal positive affective involvement factor at six months of age, or, maternal positive communication factor at twelve months of age in the PC-ERA analysis grew, the risk that a child had weak language skills at two years corrected age decreased.

\section{Discussion}

The present prospective longitudinal study provided information on the associations between the quality of early mother-child interaction and early language development in VLBW children. Most of all the findings showed that the associations between the features of the quality of mother-child interaction and language development were different in the groups of VLBW and full-term children. When measured at the same age point (i.e. at 6 or at 12 months), the features of early language

Table 2

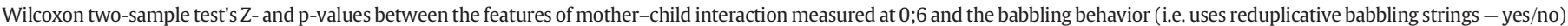
for very-low-birth-weight children (VLBW; $\mathrm{N}=28$ ) and full-term children (FT; $\mathrm{N}=34$ ) at 6 months of age.

\begin{tabular}{|c|c|c|c|c|}
\hline \multirow{3}{*}{ PC-ERA factors at $0 ; 6$} & VLBW & \multirow[b]{3}{*}{ p-value } & FT & \multirow[b]{3}{*}{ p-value } \\
\hline & $\underline{\text { Babbles at } 0 ; 6}$ & & Babbles at $0 ; 6$ & \\
\hline & $\mathrm{Z}$ & & $\mathrm{Z}$ & \\
\hline 1. Maternal positive affective involvement & -1.88 & 0.06 & -0.42 & 0.68 \\
\hline 2. Maternal negative affect and behavior & -0.66 & 0.51 & 0.30 & 0.76 \\
\hline 3. Maternal positive communication & -0.85 & 0.40 & 0.57 & 0.57 \\
\hline 4. Infant's positive affect & -1.88 & 0.06 & -1.79 & 0.07 \\
\hline 5. Infant's sober and withdrawn mood & -1.40 & 0.16 & -2.28 & 0.02 \\
\hline 6. Infants quality of play, interest and att. & -0.79 & 0.43 & -2.06 & 0.04 \\
\hline 7. Dyadic mutuality & -1.41 & 0.16 & -1.04 & 0.30 \\
\hline 8. Dyadic disorganization and tension & -0.74 & 0.46 & -1.06 & 0.29 \\
\hline 9. Dyadic flatness & -1.00 & 0.33 & -0.85 & 0.40 \\
\hline
\end{tabular}

$* p<0.05$

$* * p<0.01$.

$* * * p<0.001$ 
Table 3

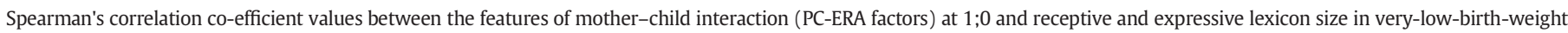
children (VLBW; $\mathrm{N}=28$ ) and full-term children (FT; $\mathrm{N}=34$ ) at 1;0.

\begin{tabular}{|c|c|c|}
\hline \multirow[t]{2}{*}{ PC-ERA factors at $1 ; 0$} & \multirow{2}{*}{$\begin{array}{l}\mathrm{CDI} ; \\
\text { Receptive lexicon size at 1;0 } \\
\mathrm{r}_{\mathrm{s}} \text { value }\end{array}$} & \multirow{2}{*}{$\begin{array}{l}\text { CDI; } \\
\text { Expressive lexicon size at } 1 ; 0 \\
r_{\mathrm{s}} \text { value }\end{array}$} \\
\hline & & \\
\hline \multicolumn{3}{|l|}{ VLBW } \\
\hline 1. Maternal positive affective involvement & 0.22 & -0.04 \\
\hline 2. Maternal negative affect and behavior & 0.25 & -0.24 \\
\hline 3. Maternal positive communication & 0.36 & 0.06 \\
\hline 4. Infant's positive affect & 0.15 & -0.15 \\
\hline 5. Infant's sober and withdrawn mood & 0.19 & -0.15 \\
\hline 6. Infants quality of play, interest and att. & 0.30 & 0.15 \\
\hline 7. Dyadic mutuality & 0.31 & -0.00 \\
\hline 8. Dyadic disorganization and tension & 0.12 & -0.08 \\
\hline 9. Dyadic flatness & 0.30 & 0.01 \\
\hline \multicolumn{3}{|l|}{ FT } \\
\hline 1. Maternal positive affective involvement & 0.17 & -0.10 \\
\hline 2. Maternal negative affect and behavior & 0.25 & 0.13 \\
\hline 3. Maternal positive communication & 0.29 & -0.03 \\
\hline 4. Infant's positive affect & -0.10 & 0.13 \\
\hline 5. Infant's sober and withdrawn mood & 0.17 & 0.27 \\
\hline 6. Infants quality of play, interest and att. & 0.18 & $0.34^{*}$ \\
\hline 7. Dyadic mutuality & $0.35^{*}$ & 0.23 \\
\hline 8. Dyadic disorganization and tension & $0.40^{* *}$ & 0.18 \\
\hline 9. Dyadic flatness & 0.30 & 0.24 \\
\hline
\end{tabular}

CDI - communicative development inventory.

$* p<0.05$.

$* * p<0.01$.

$* * * p<0.001$.

development associated significantly with the quality of mother-child interaction only in the full-term children's group. Regarding the longitudinal analysis, the significant correlations between the features of early mother-child interaction and later language skills were found in the VLBW group especially if the quality of the mother-child interaction was measured at 6 months of age, whereas many significant correlations arose when the mother-child interactions were analyzed at 12 months of age in the control group. None of the measured PC-ERA factors predicted well or excellently later language development in VLBW children. However, two maternal factors had fair predictive value for later language skills in very preterm children.

In the VLBW group, there were no associations between the features of quality of mother-child interaction and language development when analyzed at the same time point. However, in the control group, at 6 months of age, the use of reduplicative babbling strings associated significantly with two of the infant factors in the PC-ERA analysis. Although

Table 4

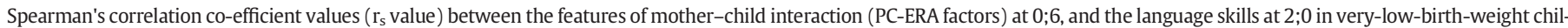
dren (VLBW; $\mathrm{N}=28$ ) and full-term children (FT; $\mathrm{N}=34$ ).

\begin{tabular}{|c|c|c|c|c|c|}
\hline \multirow[b]{2}{*}{ PC-ERA factors at 0;6 } & \multicolumn{5}{|c|}{ Language skills at $2 ; 0$} \\
\hline & $\begin{array}{l}\text { CDI; } \\
\text { lexicon size }\end{array}$ & $\begin{array}{l}\text { CDI; } \\
\text { M3L }\end{array}$ & $\begin{array}{l}\text { Speech; } \\
\text { morph. endings }\end{array}$ & $\begin{array}{l}\text { Reynell; } \\
\text { receptive }\end{array}$ & $\begin{array}{l}\text { Reynell; } \\
\text { expressive }\end{array}$ \\
\hline \multicolumn{6}{|l|}{ VLBW } \\
\hline 1. Maternal positive affective involvement & $0.52^{* *}$ & $0.46^{* *}$ & 0.36 & 0.18 & 0.32 \\
\hline 2. Maternal negative affect and behavior & 0.18 & 0.14 & 0.17 & 0.35 & 0.25 \\
\hline 3. Maternal positive communication & 0.37 & 0.32 & 0.12 & 0.03 & 0.27 \\
\hline 4. Infant's positive affect & $0.41^{*}$ & 0.22 & 0.33 & 0.21 & 0.23 \\
\hline 5. Infant's sober and withdrawn mood & 0.29 & 0.08 & 0.31 & 0.18 & 0.11 \\
\hline 6. Infants quality of play, interest etc. & $0.42^{*}$ & 0.16 & 0.36 & 0.32 & 0.19 \\
\hline 7. Dyadic mutuality & $0.39^{*}$ & 0.23 & 0.37 & 0.20 & 0.15 \\
\hline 8. Dyadic disorganization and tension & $0.58^{* *}$ & $0.45^{* *}$ & $0.58 * *$ & 0.29 & 0.29 \\
\hline 9. Dyadic flatness & 0.34 & 0.18 & 0.27 & 0.07 & 0.08 \\
\hline \multicolumn{6}{|l|}{$F T$} \\
\hline 1. Maternal positive affective involvement & -0.13 & 0.22 & $0.34^{*}$ & 0.06 & -0.04 \\
\hline 2. Maternal negative affect and behavior & 0.09 & 0.10 & 0.09 & 0.30 & -0.12 \\
\hline 3. Maternal positive communication & -0.06 & 0.27 & 0.31 & 0.08 & 0.03 \\
\hline 4. Infant's positive affect & 0.10 & 0.18 & 0.17 & 0.28 & -0.00 \\
\hline 5. Infant's sober and withdrawn mood & 0.17 & 0.28 & 0.27 & 0.30 & 0.08 \\
\hline 6. Infant's quality of play, interest etc. & 0.04 & 0.32 & 0.21 & $0.36^{*}$ & 0.03 \\
\hline 7. Dyadic mutuality & 0.05 & $0.35^{*}$ & $0.34^{*}$ & 0.26 & 0.03 \\
\hline 8. Dyadic disorganization and tension & -0.01 & $0.34^{*}$ & 0.16 & $0.35^{*}$ & 0.00 \\
\hline 9. Dyadic flatness & 0.05 & $0.34^{*}$ & $0.34^{*}$ & 0.29 & -0.01 \\
\hline
\end{tabular}

CDI - Communicative Development Inventory; M3L - the mean length of the three longest utterances calculated in morphemes; Morph. - Morphological.

$* p<0.05$.

$* * x<0.01$.

$* * * p<0.001$. 
Table 5

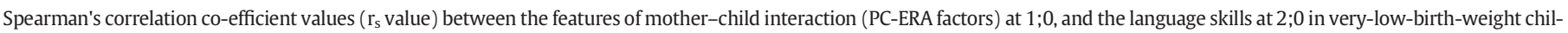
dren (VLBW; $\mathrm{N}=28$ ) and full-term children (FT; $\mathrm{N}=34$ ).

\begin{tabular}{|c|c|c|c|c|c|}
\hline \multirow[b]{2}{*}{ PC-ERA factors at $1 ; 0$} & \multicolumn{5}{|c|}{ Language skills at 2;0 } \\
\hline & $\begin{array}{l}\text { CDI; } \\
\text { lexicon size }\end{array}$ & $\begin{array}{l}\text { CDI; } \\
\text { M3L }\end{array}$ & $\begin{array}{l}\text { Speech; } \\
\text { morph. endings }\end{array}$ & $\begin{array}{l}\text { Reynell; } \\
\text { receptive }\end{array}$ & $\begin{array}{l}\text { Reynell; } \\
\text { expressive }\end{array}$ \\
\hline \multicolumn{6}{|l|}{ VLBW } \\
\hline 1. Maternal positive affective involvement & 0.15 & 0.05 & 0.13 & 0.17 & 0.10 \\
\hline 2. Maternal negative affect and behavior & -0.13 & -0.10 & -0.15 & -0.07 & -0.28 \\
\hline 3. Maternal positive communication & 0.36 & 0.21 & 0.32 & 0.33 & $0.40^{*}$ \\
\hline 4. Infant's positive affect & 0.04 & -0.05 & -0.06 & 0.11 & 0.07 \\
\hline 5. Infant's sober and withdrawn mood & 0.03 & -0.09 & -0.09 & 0.13 & 0.08 \\
\hline 6. Infants quality of play, interest etc. & 0.19 & 0.23 & 0.06 & 0.30 & 0.19 \\
\hline 7. Dyadic mutuality & 0.25 & 0.14 & 0.12 & 0.29 & 0.26 \\
\hline 8. Dyadic disorganization and tension & 0.10 & 0.03 & -0.02 & -0.02 & -0.02 \\
\hline 9. Dyadic flatness & 0.31 & 0.17 & 0.18 & 0.31 & 0.30 \\
\hline \multicolumn{6}{|l|}{ FT } \\
\hline 1. Maternal positive affective involvement & 0.12 & $0.36^{*}$ & $0.40^{* *}$ & 0.12 & 0.28 \\
\hline 2. Maternal negative affect and behavior & 0.16 & 0.06 & 0.06 & 0.29 & 0.29 \\
\hline 3. Maternal positive communication & 0.21 & $0.47^{* *}$ & $0.45^{* *}$ & 0.28 & 0.22 \\
\hline 4. Infant's positive affect & 0.13 & 0.09 & 0.15 & 0.02 & 0.18 \\
\hline 5. Infant's sober and withdrawn mood & $0.40^{*}$ & 0.33 & $0.40^{*}$ & $0.39^{*}$ & $0.34^{*}$ \\
\hline 6. Infant's quality of play, interest etc. & $0.40^{*}$ & 0.28 & $0.45^{* *}$ & $0.36^{*}$ & 0.34 \\
\hline 7. Dyadic mutuality & $0.45^{* *}$ & $0.45^{* *}$ & $0.46^{* *}$ & $0.44^{* *}$ & $0.40^{*}$ \\
\hline 8. Dyadic disorganization and tension & $0.53^{* *}$ & $0.42^{*}$ & $0.47^{* *}$ & $0.56^{* * *}$ & $0.47^{* *}$ \\
\hline 9. Dyadic flatness & $0.40^{*}$ & $0.43^{*}$ & $0.49^{* *}$ & $0.37^{*}$ & $0.42^{*}$ \\
\hline
\end{tabular}

CDI - Communicative Development Inventory; M3L - the mean length of the three longest utterances calculated in morphemes, Morph. - Morphological.

$* p<0.05$.

** $p<0.01$.

*** $p<0.001$.

the groups did not differ significantly in the use of reduplicative babbling strings at six months of age, there were more children who used reduplicative babbling strings in the full-term group at this age [26]. It is possible that this minor difference in the use of babbling strings was reflected in the PC-ERA scores. It may be that those children who used babbling strings in mother-child interactions were evaluated to have more communicative competence, and to be more socially responsive in PC-ERA analysis than those children who were silent [34]. Furthermore, at 12 months of age, one of the PC-ERA infant factor and two dyadic factors correlated with lexical measures in the full-term children. The full-term children had significantly larger receptive lexicons than VLBW children at twelve months of age [4]. The good receptive lexical development may have positively affected the dyadic interaction: it is possible that the children with good receptive lexical abilities were responsive to maternal speech, and this responsiveness positively affected maternal behavior and dyadic organization.

Many significant longitudinal correlations between the features of the quality of early mother-child interaction and later language skills were found in both groups if the quality of mother-child interaction was measured at 6 months of age. This finding supports the view that the quality of mother-child interaction has an influence on the language development of the VLBW children at least in the middle of the first year. The majority of the correlations were between dyadic factors and later language skills. It may be that the dyadic factors specifically are important for the development of language. The present finding is parallel with the finding of Landry et al. [16] who reported that

Table 6

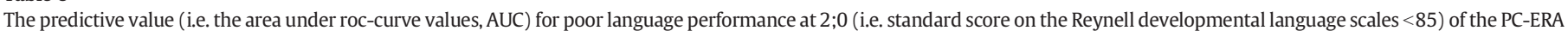
factors at $0 ; 6$ and at 1;0. The values are presented separately for the VLBW children who were growing without major neurological impairment (NI).

\begin{tabular}{|c|c|c|c|}
\hline Age & Measured PC-ERA factor & $\begin{array}{l}\text { AUC value/ } \\
\text { all VLBW children }\end{array}$ & $\begin{array}{l}\text { AUC value/ } \\
\text { VLBW children without NI }\end{array}$ \\
\hline \multicolumn{4}{|c|}{ At $0 ; 6$} \\
\hline & 1. Maternal positive affective involvement & .73 & .79 \\
\hline & 2. Maternal negative affect and behavior & .64 & .65 \\
\hline & 3. Maternal positive communication & .65 & .64 \\
\hline & 4. Infant's positive affect & .61 & .64 \\
\hline & 5. Infant's sober and withdrawn mood & .57 & .58 \\
\hline & 6. Infants quality of play, interest etc. & .66 & .59 \\
\hline & 7. Dyadic mutuality & .62 & .63 \\
\hline & 8. Dyadic disorganization and tension & .65 & .68 \\
\hline & 9. Dyadic flatness & .60 & .62 \\
\hline \multicolumn{4}{|c|}{ At $1 ; 0$} \\
\hline & 1. Maternal positive affective involvement & .62 & .64 \\
\hline & 2. Maternal negative affect and behavior & .51 & .48 \\
\hline & 3. Maternal positive communication & .72 & 69 \\
\hline & 4. Infant's positive affect & .56 & .57 \\
\hline & 5. Infant's sober and withdrawn mood & .59 & .59 \\
\hline & 6. Infant's quality of play, interest etc. & .68 & .64 \\
\hline & 7. Dyadic mutuality & .68 & .65 \\
\hline & 8. Dyadic disorganization and tension & .54 & .54 \\
\hline & 9. Dyadic flatness & .68 & .64 \\
\hline
\end{tabular}

$.90-1=$ excellent predictive value, $.80-.90=$ good, $.70-.80=$ fair, $.60-.70=$ poor, $.50-.60=$ fail. 
parenting behavior that was sensitive and not controlling and restrictive, predicted faster rates in language-cognitive development. Sensitivity can be seen to be an essential part of good dyadic interaction. Furthermore, it is also possible that the present result lifts up the developmental period for when one should support the early language development of VLBW children in mother-child interaction [21]. The optimal developmental period may be connected to brain development [21,35].

Interestingly, most of the features of the quality of mother-child interaction did not associate with later language performance if the quality of mother-child interaction was analyzed at 12 months of age in the VLBW group. It is possible that this age point is not as optimal at measuring the quality of mother-child interaction using the PC-ERA method in relation to the later language development in VLBW children as 6 months earlier. Maternal mirroring and validation of the child's communicative initiatives and signs are crucial aspects in the motherinfant interaction at the age of 6 months. These can be assessed by PCERA [31,32]. The child's early communicative initiatives are important factors in the development of the child's communication and language skills. It is possible that these matters could be assessed well at 6 months of age using the PC-ERA method, and due to this the stronger association between language development and mother-infant interaction was found at the age of 6 months compared to the age of 12 months. However, clear significant longitudinal correlations were detected in the control group if the features of mother-child interaction were analyzed at 12 months of age. The dyadic factors especially were associated significantly with later language performance in the control group. It may be that the good dyadic quality supported language development also at one year of age, at least in the full-term children. It is also possible that those children with good receptive lexicons received higher dyadic PC-ERA scores and had better language skills later because they were developing linguistically well also in the early phases of language development. Furthermore, the difference in the longitudinal correlation co-efficient values between the groups of VLBW and fullterm children could also be explained by the weaker language performance of the preterm children. Since the results of the language measures were weaker in the VLBW group [4,23], the correlation coefficient values between the PC-ERA results and language were not significant.

The findings showed that none of the PC-ERA values had good or excellent predictive value for predicting later language skills in the VLBW group. In our earlier study [22], in nearly the same group of VLBW children, the predictive value of receptive lexicon and the development of gestures at 12 and at 15 months of age were good when calculating using AUC-values. Thus, when interpreting the present finding and the finding of our earlier study together, the results suggest that biological matters may influence more on the language development of VLBW children than the contextual factors. It is possible that the biological factors influenced the language development of the VLBW children to the extent that it masked the effect of early mother-child interaction. For example, there were children who suffered from BPD in the present VLBW group. The diagnosis of BPD has been shown to be related with later, weaker language performance [36]. It is also possible that maternal interactive style has been influenced by mother's expectations about the child's communicative and linguistic potential. Thus, it may be important to support the communicative behavior of the mother especially if the preterm child has some kind of neurological diagnosis or severe illness. Ravn et al. [19] studied the effect of very early intervention on maternal depression, mother's perception on infant's temperament, breastfeeding and preterm infant's communication skill at 12 months of age. Early intervention had a significant effect on mother's depression and breastfeeding, but no impact on parenting stress and infant's communication skills. Thus, although the quality of early mother-child interaction did not have clear predictive value on language performance in the VLBW group in the present study, it may have had other important effects not measured in the present study.
Although the predictive value of the features of early mother-child interaction was generally weak, there were single factors with fair predictive value on later language performance of VLBW children. Both were maternal factors. In earlier reports, the responsiveness $[16,17]$ and the mother's use of attention-focusing gestures with relevant descriptive speech [18] have been shown to support later cognitivelanguage/language performance of preterm children. Our results give further support for the view that maternal involvement and positive communication are important parts of early mother-child interactions between preterm children and their mothers.

The strength of the present study is that it provides information on the associations between early language and mother-child interaction widely: the language skills of the VLBW children were analyzed using different methods and at different age points. Also the information on mother-child interaction was available from two age points. The limitation was the relatively small study group. It would be important to analyze the associations between early mother-child interaction and language development in a larger group of VLBW children.

This prospective study provides information on the associations between the quality of early mother-child interaction and language development in VLBW children, an area that has been analyzed in only a few studies. In the VLBW group, the features of the quality of motherchild interaction were associating significantly with later language development especially if the quality of mother-child interaction was measured at 6 months of age. This finding may lift up the optimal developmental period for when one should support the development of early language skills in VLBW children in mother-child interactions. The findings also underline the role of maternal and dyadic factors in early mother-child interactions.

\section{Conflict of interest}

The authors report no conflict of interests.

\section{Financial support}

This study has been financed by Academy of Finland, Finnish Cultural Foundation, The Emil Aaltonen Foundation and the Foundation for Paediatric Reseach.

\section{Acknowledgments}

This paper is part of the PIPARI study. Members of the PIPARI Study Group are: Satu Ekblad, Eeva Ekholm, Leena Haataja, Mira Huhtala, Pentti Kero, Riikka Korja, Harry Kujari, Helena Lapinleimu, Liisa Lehtonen, Marika Leppänen, Hanna Manninen, Jaakko Matomäki, Jonna Maunu, Petriina Munck, Pekka Niemi, Pertti Palo, Riitta Parkkola, Jorma Piha, Annika Lind, Liisi Rautava, Päivi Rautava, Milla Ylijoki, Hellevi Rikalainen, Katriina Saarinen, Matti Sillanpää, Suvi Stolt, Anniina Väliaho, Päivi Tuomikoski-Koiranen, Timo Tuovinen and Tuula Äärimaa.

\section{References}

[1] Foster-Cohen S, Edgin J, Champion P, Woodward L. Early delayed language development in very preterm infants: evidence from the MacArthur-Bates CDI. J Child Lang 2007;34:655-75.

[2] Sansavini A, Guarini A, Savini S, Broccoli S, Justice L, Alessandroni R, et al. Longitudinal trajectories of gestural and linguistic abilities in very preterm children in the second year of life. Neuropsychologia 2011;49:3677-88.

[3] Buhler K, Limongi S, de Albuquerque Diniz E. Language and cognition in very low birth weight preterm infants with PELCDO application. Arq Neuropsiquiatr 2009;67:242-9.

[4] Stolt S, Haataja L, Lapinleimu H, Lehtonen L. The early lexical development and its predictive value to language skills at 2 years in very-low-birth-weight children. J Commun Disord 2009;42:107-23.

[5] van Noort-van der Spek I, Franken M, Weisglas-Kuperus N. Language functions in preterm-born children: a systematic review and meta-analysis. Pediatrics 2012; 129:745-54. 
[6] Sansavini A, Guarini A, Justice L, Savini S, Broccoli S, Alessandroni R, et al. Does preterm birth increase a child's risk for language impairment? Early Hum Dev 2010;86:765-72.

[7] Stolt S, Matomäki J, Lind A, Lapinleimu H, Haataja L, Lehtonen L. The prevalence and predictive value of weak language skills in children with very low birth weight - a longitudinal study. Acta Paediatr 2014. http://dx.doi.org/10.1111/apa.12607 [in press].

[8] Muller-Nix C, Forcada-Guex M, Pierrehumber B, Jaunin L, Borghini A, Anserment F. Prematurity, maternal stress and mother-child interactions. Early Hum Dev 2004;79:145-58.

[9] Singer L, Fulton S, Davillier M, Koshy D, Salvator A, Baley J. Effects of infant risk status and maternal psychological distress on maternal-infant interactions during the first year of life. J Dev Behav Pediatr 2003;24:233-41.

[10] Korja R, Maunu J, Kirjavainen J, Savonlahti E, Haataja L, Lapinleimu H, et al. Motherinfant interaction is influenced by the amount of holding in preterm infants. Early Hum Dev 2008;84(4):257-67.

[11] Korja R, Ahlqvist-Björkroth S, Savonlahti E, Stolt S, Haataja L, Lapinleimu H, et al. Relations between maternal attachment representations and the quality of mother-infant interaction in preterm and full-term infants. Infant Behav Dev 2010;33(3):330-6.

[12] Wolf M-J, Koldewijn K, Beelen A, Smit B, Hedlund R, Groot I. Neurobehavioral and developmental profile of very low birth weight preterm infants in early infancy. Acta Paediatr 2002;91:930-8.

[13] Woodward L, Moor S, Hood K, Champion P, Foster-Cohen S, Inder T, et al. Very preterm children show impairments across multiple neurodevelopmental domains by age 4 years. Arch Dis Child Fetal Neonatal Ed 2009;94:F339-44.

[14] Hsu J-F, Tsai M-H, Chu S-M, Fu R-H, Chiang M-C, Hwang F-M, et al. Early detection of minor neurodevelopmental dysfunctions at age 6 months in prematurely born neonates. Early Hum Dev 2013;89:87-93.

[15] Korja R, Latva R, Lehtonen L. The effects of preterm birth on motherhood, motherinfant interaction and infant attachment during the infant's first two years. Systematic review. Acta Obstet Gynecol Scand 2012;91(2):164-73.

[16] Landry S, Smith K, Miller-Loncar C, Swank P. Predicting cognitive-language and social growth curves from early maternal behaviors in children at varying degrees of biological risk. Dev Psychol 1997;33(6):1040-53.

[17] Landry S, Smith K, Swank P, Assel M, Vellet S. Does early responsive parenting have special importance for children's development or is consistency across early childhood necessary? Dev Psychol 2001;37(3):387-403.

[18] Schmidt C, Lawson K. Caregiver attention-focusing and children's attention-sharing behaviors as predictors of later verbal IQ in very low birthweight children. J Child Lang 2002;29:3-22.

[19] Ravn I, Smith L, Smeby N, Kynoe N, Sandvik L, Bunch E, et al. Effects of early motherinfant intervention on outcomes in mothers and moderately and late preterm infants at age 1 year: a randomized controlled trial. Infant Behav Dev 2012;35:36-47.
[20] Landry S, Smith K, Swank P, Guttentag C. A responsive parenting intervention: the optimal timing across early childhood for impacting maternal behaviors and child outcomes. Dev Psychol 2008;44(5):1335-53.

[21] Malekpour M. Low birth-weight infants and the importance of early intervention: enhancing mother-infant interactions. A literature review. $\mathrm{Br} J$ Dev Disabil 2004;99:78-88.

[22] Stolt S, Mäkilä A-M, Matomäki J, Lehtonen L, Lapinleimu H, Haataja L. The development and predictive value of gestures in very-low-birth-weight children: a longitudinal study. Int J Speech Lang Pathol 2014. http://dx.doi.org/10.3109/17549507. 2013.794861 [in press].

[23] Stolt S, Lehtonen L, Haataja L, Lapinleimu H, the PIPARI Study Group. The language used in early mother-child interaction by very-low-birth-weight children, with a focus on the emergence of grammar. Logopedia Foniatria Audiologia 2011;31(3):115-24.

[24] Bayley N. The Bayley scales of infant development. 2nd ed. San Antonio, TX: Psychological Corporation; 1993.

[25] Lyytinen P, Ahonen T, Eklund K, Lyytinen H. Ääntelyn ja motoriikan kehityksen seurantamenetelmä. Jyväskylä: Niilo Mäki Instituutti; 2000.

[26] Stolt S, Lehtonen L, Haataja L, Lapinleimu H. Development and predictive value of early vocalizations in very-low-birth-weight children - a longitudinal study. Clin Linguist Phon 2012;26(5):414-27.

[27] Fenson L, Dale P, Reznick J, Bates E, Thal D, Pethick S. Variability in early communicative development. Monogr Soc Res Child Dev 1994:59 [5, Serial No. 242].

[28] Lyytinen P. Varhaisen kommunikaation ja kielen kehityksen arviointimenetelmä. Jyväskylän yliopiston Lapsitutkimuskeskus ja Niilo Mäki instituutti. Jyväskylä: Niilo Mäki Säätiö; 1999.

[29] Edwards S, Fletcher P, Garman M, Hughes A, Letss C, Sinka I. Reynell developmental language scales. 3rd ed. manual. Berkshire, UK: The NferNelson Publishing Compary Limited; 1997.

[30] Kortesmaa K, Merikoski H, Warma M-L, Varpela V. Reynellin kielellisen kehityksen testi. Helsinki: Psykologien kustannus Oy; 2001.

[31] Clark R. The parent-child relational assessment; instrument and manual. Madison: University of Wisconsin Madison Medical School, Dept. of, Psychiatry; 1995.

[32] Clark R. The parent-child early relational assessment: a factorial validity study. Educ Psychol Meas 1999;9:821-46.

[33] Tape T. The area under an ROC curve. Retrieved 10.102011 from the University of Nebraska Medical Center web-site address: http://gim.unmc.edu/dxtests/ROC3. htm; October 2011.

[34] Masataka N, Bloom K. Acoustic properties that determine adults' preferences for 3month-old infant vocalizations. Infant Behav Dev 1994;17:461-4.

[35] Bonnier C. Evaluation of early stimulation programs for enhancing brain development. Acta Paediatr 2008;97:853-8.

[36] Lewis B, Singer L, Fulton S, Salvator A, Short E, Klein N, et al. Speech and language outcomes of children with bronchopulmonary dysplasia. J Commun Disord 2002;35:393-406. 